\title{
Hōs me e o sentido da carne: um olhar sobre o homo sacer contemporâneo
}

\author{
Hōs me and the sense of flesh: a look upon contemporary homo sacer
}

\author{
Ricardo Geraldo de Carvalho* \\ Glauco Barsalini**
}

\section{RESUMO}

Com a máxima "Pois quando sou fraco, então é que sou forte", Paulo Apóstolo convoca as pessoas a fazerem um novo uso de si, tornando-se libertas na medida em que se prestem a servir a Deus. Atento ao problema da exclusão (inclusiva), própria à modernidade, motivo do reaparecimento do homo sacer no mundo atual, Giorgio Agamben relê a tese paulina e, ao propor um novo uso da teologia, coloca no centro do debate científico o termo hōs me (como não), apresentando possíveis saídas para a dissolução da violência política e jurídica que é, para ele, na história moderna, responsável pela criação da tensão entre a civilização e a barbárie. Nesse contexto, o homo sacer (vida nua) pode ser compreendido menos como a máxima expressão da finitude e mais como a revelação extrema da potência humana, a justificar o abandono dos mecanismos que o recriam e, com isso, o início de uma nova condição de humanidade.

Palavras-chave: Hōs me. Sarx. Basar. Homo sacer. Giorgio Agamben. Apóstolo Paulo.

\section{ABSTRACT}

With the sentence "For when I am weak, then I am strong," Paul the Apostle calls people to make a new use of themselves, becoming free as they serve God. Attentive to the problem of the exclusion of modernity, which is the reason for the reappearance of the homo sacer in the present world, Giorgio Agamben reread the Pauline thesis and proposes a new use of theology, inserting at the center of scientific debate the term hōs me (as not) presenting possibilities for the dissolution of political and juridical violence that is, for him, in modern history, responsible for creating tension between civilization and barbarism. In this context homo sacer (naked life) can be understood less as the ultimate expression of finitude and more as the extreme revelation of human power, which justifies the abandonment of the mechanisms that recreate it and, thus, the beginning of a new condition of humanity.

Keywords: Hōs me. Sarx. Basar. Homo sacer. Giorgio Agamben. Paul the Apostle.

\footnotetext{
* Graduado em Filosofia pela PUC-Campinas e Teologia pelo ITESP. Mestre em Ciências da Religião pela PUC-Campinas.<rg77carvalho@ gmail.com>.

** Doutor em Filosofia pela Universidade Estadual de Campinas. Professor Pesquisador do Programa de Pós-Graduação em Ciências da Religião e da Faculdade de Ciências Sociais da PUC-Campinas.<glaucobarsalini@gmail.com>
} 


\section{INTRODUÇÃO}

No âmbito da Teologia Política, o filósofo italiano Giorgio Agamben trilha percurso intelectual inovador e provocativo, ousando fazer um novo uso da teologia ocidental, com o fito de compreender o poder e os seus efeitos nas sociedades moderna e contemporânea. Assim, desenvolve o Programa Homo Sacer que, embora o autor afirme ser datado - com início pela obra Homo Sacer: O poder soberano e a vida nua I, e fim com o livro $O$ uso do corpos: homo sacer IV, 2 - tem o seu anúncio, ainda que de modo não explícito, já em suas primeiras obras e, ainda, após o último volume e no mais no que continua a escrever e a publicar.

Defende a ideia de que, desde a modernidade, o poder soberano constrói-se violentamente, encerrando em si um duplo movimento: o da exclusão inclusiva e, ao mesmo tempo, o da inclusão exclusiva. Nesse modelo muitas pessoas podem ser excluídas da condição de cidadãs, a qualquer instante, ou religadas, de algum modo, ao universo dos direitos, em algum outro momento. Para Agamben, vivemos em um estado de exceção permanente, de modo que até o maior exemplo de democracia contemporânea revela, em si, a presença de dispositivos de controle, assujeitamento e da mais radical exclusão de seres humanos, fazendo reaparecer, na atualidade, certa condição humana que pode ser melhor compreendida pelo resgate conceitual de uma antiga figura do direito romano, o homo sacer, sujeito - real - de não direitos do mundo romano, a quem se relegava a condição de poder ser morto sem que seu extermínio implicasse em pena a quem o fizesse.

Contextualizado nas sociedades em que o poder sobre a vida (biopoder) pelo uso da técnica e de seu produto - a tecnologia - têm caráter totalizante, o homo sacer contemporâneo é, pois, vida nua, vida exposta que, longe de possuir qualquer status jurídico, é alcançada pelo direito nos momentos em que o poder soberano decide fazêlo. Nesse sentido, em situação de extrema vulnerabilidade, o homo sacer é aquele que está no estágio de transitoriedade do humano para o inumano ${ }^{1}$.

Interessa, neste artigo, discutir-se a condição desse ser humano que não vive nem a humanidade na sua integralidade e nem, tampouco, a inumanidade, dado ser ele propriamente humano e, por isso, ainda enquanto vida nua, pertencente à espécie. Objetiva-se, também, refletir-se - a partir dessa mesma figura (o homo sacer) e no caminho interpretativo que Agamben propõe a respeito de São Paulo - acerca das possibilidades concretas de dissolução dos dispositivos excludentes constitutivos do poder soberano hodierno.

\section{0 "COMO NÃO” E O SENTIDO DA CARNE}

Em O uso dos corpos, Agamben investiga o pensamento do apóstolo Paulo detendo-se, fundamentalmente, aos escritos paulinos destinados à Comunidade de Corinto e à Comunidade de Roma. Neste ínterim, em uma das cartas escritas para um grupo de coríntios, na qual revela sua conversão ao Projeto de Vida anunciado por Jesus de Nazaré, o apóstolo assevera: "Pois quando sou fraco, então é que sou forte" (2Co 12,10).

Segundo o teólogo Jean Zumstein, que analisa a cruz como princípio de constituição da teologia paulina, o apóstolo está seguindo fielmente a proposta do Nazareno, o seu Senhor, que foi crucificado na fraqueza, mas que está vivo pela graça de

\footnotetext{
${ }^{1}$ AGAMBEN, G. O que resta de Auschwitz: o arquivo e a testemunha.
} 
Deus $(2$ Co 13,4). Logo, pode-se afirmar que a força manifesta-se na fraqueza, ou seja, "a minha graça te basta; o meu poder se perfaz na fraqueza"2.

A questão é radicalmente pertinente e permanece atual. Agamben apresenta o ser vivo como capaz de fazer uso de si em seu percurso vital, segundo o qual implica relacionar com outro de si, pois a cada instante do concatenar de si, "sente a si e se familiariza consigo mesmo. O si nada mais é do que o uso de si" transcende a si mesmo, haja vista que gera o limite entre essência e existência. Para tanto, o si necessita ser significativo no uso, entretanto, desvinculado de toda e qualquer substancialidade, para que se assuma enquanto sujeito da situação em voga. Nesta problemática, o pensador dialoga com a teoria messiânica, elaborada pelo Apóstolo Paulo em sua primeira epístola à Comunidade de Corinto:

'Foste chamado na condição de escravo?', escreve ele. 'Não te preocupes com isso; mas, se também podes tornar-te livre, faz uso' (mallon chresai-ou seja, de tua condição de escravo - 1 Coríntios 7,21). As condições factícias e jurídicopolíticas em que cada um se acha não devem, pois, ser hipostasiadas nem simplesmente modificadas. A chamada messiânica não confere nova identidade substancial, mas consiste, acima de tudo, na capacidade de 'usar' a condição factícia em que cada um se encontra ${ }^{4}$.

Ao fazer a arqueologia da primeira carta de Paulo aos Coríntios, Agamben destaca a expressão como não (hōs me), como sendo entendida a partir de uma nova capacidade de uso. Neste contexto, o apóstolo escreve:

Portanto digo, irmãos, o tempo se abreviou; o que resta é que os que têm mulher sejam como não [hōs $m e]$ a tivessem, os que choram, como não chorantes, os que se alegram, como não se alegrando, os que compram, como nada possuindo, e os que usam do mundo, como dele não abusando. De fato, a figura desse mundo passa. Quero que estejais sem cuidado (1Co 7,29-32).

O jusfilósofo continua seu aprofundamento acerca da expressão paulina como não, lançando luzes na tensão ocasionada pela condição da provisoriedade dos fatos. Destarte, Agamben afirma:

O “como não" paulino, tensionando cada condição factícia consigo mesma, a cancela e desativa sem alterar sua forma (os que choram como não chorantes, os que têm mulher como não a tivessem, escravos como não escravos). A vocação messiânica consiste, pois, na desativação e na desapropriação da condição factícia, que, dessa forma, se abre para um novo uso possível. A 'nova criatura' nada mais é do que a capacidade de tornar inoperosa e usar de modo novo a antiga: "Se alguém está no messias, é nova criatura [kainè ktisis]: as coisas antigas passaram, eis que se fizeram novas" (2Cor 5,17$)$.

Dessa forma, entende-se melhor o sentido das antíteses dos versículos 30-31: 'Os que compram, como se nada possuíssem, e os que usam do mundo, como se dele não abusassem'. O que está em questão é uma referência explícita à definição da propriedade segundo o direito romano como ius utendi et abutendi. Assim, Paulo contrapõe o usus ao dominium: ficar na chamada na forma do 'como não' significa nunca fazer do mundo um objeto de propriedade, só de uso. ${ }^{6}$

${ }^{2}$ ZUMSTEIN, J. A cruz como princípio de constituição da teologia paulina, p. 324-325.

${ }^{3}$ AGAMBEN, G. O uso dos corpos: Homo Sacer IV, 2, p. 76.

${ }^{4}$ AGAMBEN, G. O uso dos corpos: Homo Sacer IV, 2, p. 78.

${ }_{5}^{5}$ AGAMBEN, G. O uso dos corpos: Homo sacer, IV, 2, p. 78.

${ }^{6}$ AGAMBEN, G. O uso dos corpos, Homo sacer, IV, 2, p. 78-79. 
Agamben associa a contiguidade entre a potência destituinte e a condição da mais extrema vulnerabilidade humana ao termo "inoperosidade". Segundo o filósofo italiano, tanto na potência destituinte, como na inoperosidade, está em pauta a capacidade de transformar, ou seja, desativar uma realidade incrustada no poder, na função, ou mesmo na operação humana, tornando-a inoperante. Sem simplesmente destruir a situação, "mas libertando as potencialidades que haviam ficado não atuadas a fim de permitir, dessa maneira, um uso diferente". Neste cenário o Apóstolo Paulo não estimulava a destruição da lei ("santa e justa"), mas impelia à desativação de sua funcionalidade no tocante ao pecado. Na epístola à Comunidade de Roma o jusfilósofo resgata Paulo discorrendo sobre a problemática da lei: "Eu não teria conhecido o desejo, se a lei não tivesse dito: 'Não desejarás; tomando impulso a partir do mandamento, o pecado tornou operante [kateirgasato, 'ativo'] em mim todo desejo" (Rm 7,8)7, do que infere Agamben:

A lei que é 'defendida' é destituída de seu poder de comando, ou seja, é uma lei não mais dos mandamentos e das obras (nomos ton entolon-Efésios 2.15; ton ergon - Romanos 3.27), mas da fé (nomos pisteos - idem). E a fé não é essencialmente uma obra, mas uma experiência da palavra ('a fé da escuta e a escuta por meio da palavra' - [ibidem,] $10.17^{8}$.

Entende-se, aqui, que a relação existente entre o pensamento do Apóstolo Paulo e a proposta reflexiva do jusfilósofo Giorgio Agamben apresenta similaridades na centelha que permanece aquecendo a vida, mais precisamente, a sobrevida dos seres humanos em situações extremas, (ponto ou vírgula?) a vida nua, totalmente fragilizada, desumanizada pelo poder sobre a vida, resgata no cerne divino da alma uma força que a faz encontrar um sentido humanizador na realidade em que se criam, por sistema sombrio e monstruoso, técnicas para extirpar todo ânimo existencial da pessoa em situação de grande vulnerabilidade. A finitude submersa no estado de exceção, travestido de epifenômeno, tem o seu instante epocal no eclodir da amorosidade à vida no interior mais profundo do homo sacer, gerando, nele, a verdadeira liberdade, a liberdade interior; a inquietude criativa capaz de transpor o sofrimento mais atroz, "pois quando sou fraco, então é que sou forte" (2Co 12,10).

Ao escolher o caminho do apostolado de Cristo, Paulo passou a ser alvo da violência soberana. Não se trata de hiperbolismo afirmar que o apóstolo Paulo experienciou uma verdadeira via crucis. Seus compatriotas o acusavam de traidor, pois ele ousava proclamar o fim da lei mosaica e das tradições religiosas do povo hebreu.

Ora o instigavam contra as autoridades locais (At 16,16ss.); ora o golpeavam diretamente, infligindo-lhe as costumeiras penas previstas no código disciplinar das sinagogas: 'Cinco vezes recebi dos judeus os trinta e nove golpes de chicote... Uma vez sofri o apedrejamento' (2Cor 11,24-25). Chegaram a ameaçar-lhe seriamente a vida, como ele mesmo confessa aos cristãos de Roma (Rm 15, 30-31). Em Éfeso esteve a um passo da morte. ${ }^{9}$

Barbaglio infere que as perseguições sofridas por Paulo são um pequeno sinal de uma vida difícil e marcada por adversidades e sofrimentos. Todavia, ele não se deixava abater e tão pouco rendia-se às intempéries. Em 2Co o apóstolo retoma o axioma: "Não perdemos o ânimo" (4.1.16); "estamos cheios de coragem" (5.6.8). Cônscio de sua

\footnotetext{
${ }^{7}$ PAULO apud AGAMBEN, G. O uso dos corpos: Homo Sacer IV, 2, p. 305.

8 AGAMBEN, G. O uso dos corpos: Homo sacer, IV, 2, p. 305-306.

${ }^{9}$ BARBAGLIO, Giuseppe. As cartas de Paulo I: Tradução e Comentário, p. 37.
} 
trajetória existencial, Paulo consegue experienciar uma alegria inebriante: "O consolo plenifica meu coração, e transbordo de alegria em todas as nossas aflições" (2Co 7,4; cf. 2Co 6,10; Fl 1,4.7.18; 2,17-18) ${ }^{10}$.

$\mathrm{Na}$ verdade, ele soube perceber, em sua vida crucificada, a expressão de uma profunda participação na cruz de Cristo. Seus sofrimentos são os sofrimentos de Cristo (2Co 1,5); em sua pessoa carrega 'a morte de Jesus' (2Co 4,10); aos gálatas diz: "Trago em meu corpo os estigmas de Jesus" (6,17). Falou-se de mística paulina, mas o termo não deve induzir-nos em erro. Parece preferível falar de uma aguda intuição: em sua existência se realiza a história da salvação, vista em sua lógica desconcertante e escandalosa, de vida que nasce da morte, de criação a partir do nada. Explica-se assim o paradoxo posto diante dos olhos dos coríntios: 'somos atribulados por todos os lados, mas não esmagados; desorientados, mas não desesperados; perseguidos, mas não abandonados; derrubados, mas não aniquilados; trazemos continuamente em nosso corpo a morte de Jesus, para que também a vida de Jesus se manifeste em nosso corpo... Assim, em nós opera a morte, mas em vocês, a vida' (2Co 4,8-12); 'É na fraqueza que a força se manifesta. (...) Cristo crucificado e ressuscitado revive em sua carne: Sim, por fraqueza ele foi crucificado, mas vive pela força de Deus. Nós também somos fracos nele, mas viveremos junto com ele pela força de Deus que se manifesta para vocês' $(2$ Co 13,4). Entre uma mensagem e outra, há uma substancial continuidade: o que Paulo anuncia, ou seja, o mistério da morte e ressurreição de Cristo, é vivida em sua existência apostólica. Em poucas palavras, o evangelho, anunciado por sua palavra fica plasticamente evidenciado por sua vida crucificada, na qual a fraqueza humana conjuga-se com a força criadora de Deus. ${ }^{11}$

$\mathrm{Na}$ antropologia paulina o termo sarx "carne" tem grande relevância - emergindo 91 vezes nas cartas do Apóstolo, das quais 26 na Carta aos Romanos -, mesmo sendo antagônico em função da abrangência de sua utilização. O pensamento regente do último século funda-se na interpretação segundo a qual Paulo reflete uma combinação de influências judaicas e helenísticas com intensidade adequada ao contexto onde evangelizava. Nesta perspectiva, a ideia de sarx enquanto corpo físico abarca o sentido hebraico de basar, embora a ideia de sarx no que concerne um antagonismo a Deus resultasse da tradição helênica. Paulo peregrina por uma reflexão bastante tênue ao considerar a carne (corporeidade) absolutamente falha e interpretá-la como ativamente antitética e hostil a Deus. No bojo do seu discurso, constata-se que suas palavras sustentam-se sobre a fraqueza e a corruptividade da carne, porque a vida experenciada nesse nível ou por ele delineada está fadada à morte $(\mathrm{Rm} 8,6.13)$. Por outro lado, ao aproximar-se do conceito hebraico de basar, o Apóstolo confere também conotação libertadora à carne, entendida, aqui, enquanto potência. Ao associar sarx a basar, o Apóstolo assume, portanto, outras dimensões no que concerne à condição humana ${ }^{12}$. James D. G. Dunn afirma:

A concepção paulina da pessoa humana é a de um ser que funciona dentro de várias dimensões. Como seres corporificados, somos sociais, definidos em parte pela nossa necessidade e nossa capacidade de entrar em relação, não como um opcional extra, mas como uma dimensão da nossa própria existência. Nossa carnalidade atesta nossa fragilidade e fraqueza como meros humanos, a

${ }^{10}$ BARBAGLIO, Giuseppe. As cartas de Paulo I: Tradução e Comentário, p. 37-38.

${ }^{11}$ BARBAGLIO, Giuseppe. As cartas de Paulo I: Tradução e Comentário, p. 38-39.

${ }^{12}$ DUNN, J. D. G. A teologia do Apóstolo Paulo, p. 93-99. 
inevitabilidade da nossa morte, nossa dependência da satisfação dos apetites e desejos. Ao mesmo tempo, como seres racionais, somos capazes de nos alçar às maiores alturas do pensamento reflexivo. E como seres humanos que sentem somos capazes das mais profundas emoções e da mais intensa motivação. Somos seres vivos, animados pelo mistério da vida como um dom, e há uma dimensão do nosso ser pela qual somos diretamente tocados pela realidade mais profunda dentro e além do universo. Paulo não duvidaria em dizer, grato e reconhecido, com o salmista: 'Eu te celebro por tão grande prodígio, eu me maravilho com as tuas maravilhas' $(\mathrm{S} 1 \mathrm{139}, 14)^{13}$.

A combinação entre sarx e basar revela a ambivalência própria ao ser humano: de um lado a sua fragilidade e, de outro, a sua potência. Capaz de humanizar-se e de humanizar a vida coletiva, o ser humano, quando alijado à condição de homo sacer, embora impossibilitado de relacionar-se socialmente, não perde, porque não há como perder, o que o constitui enquanto sarx. Continua, portanto, fraco, de um lado, e forte, de outro, pois, ainda que, agora, vida nua, permanece vida humana.

No livro intitulado $O$ que resta de Auschwitz, o jusfilósofo Giorgio Agamben apresenta o drama extremo vivido pelas pessoas aprisionadas no campo de concentração de Auschwitz, onde sobreviver significava tornar-se uma testemunha:

De minha parte, tinha decidido firmemente que, independente do que me viesse a acontecer, não me teria tirado a vida. Queria ver tudo, viver tudo, fazer experiência de tudo, conservar tudo dentro de mim. Com que objetivo, dado que nunca teria tido a possibilidade de gritar ao mundo aquilo que sabia? Simplesmente porque não queria sair de cena, não queria suprimir a testemunha que podia me tornar ${ }^{14}$.

Neste cenário sóbrio em que a vida humana preterida pelo biopoder deixou de ser cuidada e valorizada, passando a ser tratada como um mero aglomerado de funções biológicas, apresentam-se testemunhos:

Certamente nem todos, ou melhor, só uma parte ínfima dos detidos invoca para si mesma essa razão. De resto, também pode acontecer que se trate de uma razão cômoda ['gostaria de sobreviver por esse ou aquele motivo, por esse ou aquele objetivo, e se encontram centenas de pretextos. A verdade é que se gostaria de viver a qualquer preço']. Ou então pode tratar-se apenas de vingança ['naturalmente poderia suicidar-me lançando-me sobre a cerca elétrica, isso sempre podemos fazê-lo. Mas eu quero viver. Quem sabe aconteça um milagre e seremos libertados. E então irei me vingar, contarei a todo o mundo o que aconteceu aqui dentro']. Justificar a própria sobrevivência não fácil, menos ainda no campo. Além disso, alguns sobreviventes preferem ficar em silêncio. 'Alguns dos meus amigos, amigos que me são muito caros, nunca falam de Auschwitz'. No entanto, para outros a única razão de viver é não permitir que a testemunha morra. 'Outras pessoas, por sua vez, falam disso sem parar, e sou um deles' ${ }^{15}$.

Ao fazer a filologia do termo testemunha, Agamben resgata do grego a palavra martis, ou seja, a testemunha é um mártir. Os padres dos primórdios da Igreja definiam o termo martirium desta relação, haja vista que os primeiros cristãos, mortos pela

${ }^{13}$ DUNN, J. D. G. A teologia do Apóstolo Paulo, p. 112.

${ }^{14}$ LANGBEIN, H. apud AGAMBEN, G. O que resta de Auschwitz: o arquivo e a testemunha, p. 25.

${ }^{15}$ AGAMBEN, G. O que resta de Auschwitz: o arquivo e a testemunha, p. 25-26. 
perseguição do Império Romano, testemunhavam sua fé. O genocídio ocorrido contra judeus, ciganos, portadores de necessidades especiais, grupos minoritários e contrários ao regime nazista acontecido no campo de concentração assemelha-se ao martírio cristão. Mediante esta afirmativa, as narrativas dos sobreviventes são congruentes: "Chamando as vítimas dos nazistas de 'mártires', falsificamos seu destino"16. Neste ínterim, há dois pontos em que estas duas realidades parecem aproximar-se. O primeiro aspecto relaciona-se com o próprio termo grego, que advém de um verbo que denota "recordar". O sobrevivente nutre em sua identidade a memória, a capacidade de recordar. Neste contexto, Primo Levi narra:

As recordações do meu cativeiro estão muito mais vivas e detalhadas do que qualquer outra coisa que aconteceu antes ou depois.

Conservo uma memória visual e acústica das experiências de lá que não consigo explicar [...] ficaram-me gravadas na mente, como se estivessem numa fita magnética, frases em línguas que não conheço, em polonês ou em húngaro; ao repeti-las a poloneses e húngaros, me disseram que frases têm sentido. Por algum motivo que não conheço, aconteceu-me algo de anômalo, diria quase uma preparação inconsciente para testemunhar ${ }^{17}$.

Todavia, no segundo aspecto, a relação demonstra ser mais íntima e instrutiva, pois a doutrina do martírio nasce para justificar o escândalo de uma morte insensata, de uma carnificina que não podia deixar de parecer absurda. Perante a situação segundo a qual se mata outrem, aparentemente sine causa, conforme observa-se nos Evangelhos de Lucas 12.8-9 e Mateus 10.32-33 ("todo aquele que me confessar diante dos homens, também eu o confessarei diante de meu Pai; e aquele que me negar diante dos homens, também eu o renegarei diante de meu Pai") se podia interpretar o martírio "como um mandamento divino e que se encontrasse assim uma razão para o irracional"18.
Mas isso tem muito a ver com os campos. Com efeito, nos campos, o extermínio - para o qual talvez fosse possível encontrar precedentes - apresenta-se, porém, em formas que o tornam absolutamente sem sentido. Também a respeito disso os sobreviventes se acham concordes. 'A nós mesmos, o que se tinha a dizer então começou a parecer inimaginável' (ANTELME apud AGAMBEN, 2008, p. 37). 'Todas as tentativas de explicação [...] fracassaram radicalmente' (AMÉRY apud AGAMBEN, 2008, p. 37). 'Irritam-me as tentativas de alguns extremistas religiosos que interpretam o extermínio à maneira dos profetas: uma punição para os nossos pecados. Não! Isso não o aceito. $\mathrm{O}$ fato de ser insensato torna-o mais espantoso'19.

A utilização inadequada do termo "holocausto" é proveniente dessa inconsciente exigência de justificar a morte sine causa, de atribuir um sentido ao que parece não poder ter sentido. O termo "Holocausto" é a transcrição doutrinada do latino holocaustum, o qual traduz o termo grego holókaustos (um adjetivo que significa literalmente "todo queimado"; o substantivo grego correspondente é holokaústoma). Consta na história semântica deste termo que ele é eminentemente cristão, visto que os padres da Igreja primitiva apropriaram-se dele para traduzirem, sem muito rigor e coerência, a complexa doutrina sacrifical da Bíblia, contidas fundamentalmente nos livros do Levítico e dos

\footnotetext{
${ }^{16}$ BETTELHEIM, B. apud AGAMBEN, G. O que resta de Auschwitz: o arquivo e a testemunha, p. 35

${ }^{17}$ LEVI apud AGAMBEN, G. O que resta de Auschwitz: o arquivo e a testemunha, p. 36.

${ }^{18}$ AGAMBEN, G. O que resta de Auschwitz: o arquivo e a testemunha, p. 37.

${ }^{19}$ LEVI, P. apud AGAMBEN, G. O que resta de Auschwitz: o arquivo e a testemunha, p. 37.
} 
Números. Os léxicos contemporâneos registram que o termo holocausto terá sua adequação semântica, fazendo-o mais consistente, nas línguas vulgares, para atingir o significado de "sacrifício supremo, no marco de uma entrega total a causas sagradas e superiores". Na tentativa de explicar o extermínio com uma terminologia mais precisa e sem arcaísmos antissemitas, os judeus recorrem a um eufemismo:

Trata-se do termo shoá, que significa 'devastação, catástrofe' e, na Bíblia, implica muitas vezes a ideia de uma punição divina ('Pois bem, que fareis no dia da visitação, quando a ruína vier de longe?'). Mesmo que seja provavelmente a esse termo que se refere Levi, ao falar da tentativa de interpretar o extermínio como uma punição pelos nossos pecados, o eufemismo aqui não contém escárnio algum. Pelo contrário, no caso do termo 'holocausto', estabelecer uma vinculação, mesmo distante, entre Auschwitz e o olah bíblico, e entre a morte nas câmaras de gás e a 'entrega total a causas sagradas e superiores' não pode deixar de soar como zombaria. O termo não só supõe uma inaceitável equiparação entre fornos crematórios e altares, mas acolhe uma herança semântica que desde o início traz uma conotação antijudaica. ${ }^{20}$

Agamben define a shoá como sendo uma situação sem testemunhas no duplo sentido, "de que sobre ela é impossível testemunhar tanto a partir de dentro - pois não se pode testemunhar de dentro da morte, não há voz para a extinção da voz - quanto a partir de fora - pois o outsider é excluído do acontecimento por definição"21. O jusfilósofo continua:

Aquilo de que dá testemunho não pode ser já língua, já escritura: pode ser somente um não-testemunhado. Isso é o som que provém da lacuna, a não língua que se fala sozinho, de que a língua responde, em que nasce a língua. $\mathrm{E}$ é sobre a natureza deste não-testemunhado, sobre a não-língua que é preciso interrogar-se.

(...) A língua do testemunho é uma língua que não significa mais, mas que, nesse seu ato de não-significar, avança no sem-língua até recolher outra insignificância, a da testemunha integral, de quem, por definição, não pode testemunhar. Portanto, para testemunhar, não basta levar a língua até ao próprio não-sentido, até à pura indecidibilidade das letras (m-a-s-s-k-l-o, m-a-t-i-s-k1-o); importa que o som sem sentido seja, por sua vez, voz de algo ou alguém que, por razões bem distintas, não pode testemunhar. Assim, a impossibilidade de testemunhar, a "lacuna" que constitui a língua humana, desaba sobre si mesma para dar lugar a uma outra impossibilidade de testemunhar - a daquilo que não tem língua.

O sinal, que a língua julga transcrever a partir do não testemunhado, não é a sua palavra. É a palavra da língua, a que nasce lá onde a língua já não está no seu início, deriva disso a fim de - simplesmente - testemunhar: "não era luz, mas estava para dar testemunho da luz'22.

Segundo o filósofo e linguista búlgaro Tzvetan Todorov, ao pensar-se o ser humano dotado de afetos, sentimentos, emoções, enfim, estímulos provenientes do espaço onde ele está inserido, pode-se observar o intestemunhável, na medida em que as pessoas estão absortas em um cenário desumanizador e fantasmagórico do estado de exceção,

${ }^{20}$ AGAMBEN, G. O que resta de Auschwitz: o arquivo e a testemunha, p. 40.

${ }^{21}$ AGAMBEN, G. O que resta de Auschwitz: o arquivo e a testemunha, p. 40.

${ }^{22}$ AGAMBEN, G. O que resta de Auschwitz: o arquivo e a testemunha, p. 47-48. 
que tenta com métodos abomináveis capturar a alma dos indivíduos submergidos por este poder sobre a vida. Mas talvez não seja indispensável transformar a noção de moral para contestar a ideia popular de que Auschwitz revelara a imoralidade essencial do ser humano. Uma leitura mais atenta dos testemunhos demonstra que a vida moral não se extinguiu no interior dos campos de concentração; ela apenas se transformou. Não há narrativas sobre a vida no campo que não citem também atos de generosidade, de dignidade, de elevação do espírito. Essas atitudes não retratam o testemunho de todos, e não ocorrem o tempo todo; todavia, elas nunca desaparecem inteiramente. Esta reflexão pode gerar o seguinte questionamento: por que Améry, Levi, Chalamov e Guinzbourg insistem em aderir à concepção de Hobbes, mesmo que seus relatos a refutem? É provável que se trate, nesse caso, de um desejo perfeitamente compreensível de não embelezar o passado, mas sim de evidenciar o que ele possuía de mais excessivo ${ }^{23}$.

Por conseguinte, existe um limiar segundo o qual as reações dos indivíduos não informam nada além da própria circunstância, acarretando um estado de extrema dilaceração da própria identidade, em que a pessoa não consegue reconhecer ou esperançar por uma vida normal, perdendo o sentido de sua vida. Perante a negação do humano, depara-se com problemáticas que feriram, e ainda ferem, a alma da humanidade:

No século XX, surgiu a ideia pela qual algumas situações humanas extremas lançam uma nova luz sobre as condutas morais e permitem, melhor, compreendêlas. As situações extremas são percebidas como condições de laboratório, onde é possível observar, como sob uma lupa, os seres humanos que, na sua existência ordinária, dissimulam e falsificam sua verdadeira natureza. $O$ termo e a ideia aparecem, pela primeira vez, nos escritos do psiquiatra Bruno Betteheim, no dia seguinte à sua libertação do campo de concentração de Buchenwald. Ele observou comportamentos psíquicos e morais que lhe parecem diferentes dos que são percebidos no mundo fora dos campos e que, todavia, contribuem para a melhor compreensão dos mesmos. Mais tarde, a noção de situação extrema foi expandida dos campos nazistas para outros campos totalitários nos países comunistas (na URSS, na China, no Camboja, na Bulgária), assim como em outras situações excepcionais, consecutivas a catástrofes naturais ou mecânicas, a sequestros ou encarceramentos em condições particularmente desumanas.

(...) As situações extremas dos campos transformam o comportamento de dois grupos de pessoas que podemos chamar de detentos e guardiães. No que se refere aos detentos, a observação mais frequente das próprias testemunhas, sejam elas filósofos, psicólogos ou simples vítimas, é: a vida moral dos indivíduos encontra-se reduzida a zero ${ }^{24}$.

Todorov, em sua dissertação, resgata o drama absoluto experenciado pelas pessoas mais vulneráveis em situações extremas ocorridas pelo estado de exceção e ratifica:

Terrence Des Pres, (...) pensou poder recusar a conclusão a partir de uma redefinição do que é moral. Nós confundimos, pensa ele, a moral com o altruísmo; ora, se nos colocarmos com Des Pres numa perspectiva sociobiológica, podemos afirmar que, em situações extremas, aspirar à nossa própria sobrevivência é um ato moral, e não somente um reflexo de autoconservação. $\mathrm{O}$ objetivo dos guardiães é a morte dos detentos; lutando pela sua sobrevivência, eles afirmam o direito de viver, o que é um valor moral.

${ }^{23}$ TODOROV, T. Situações Extremas, p. 960.

${ }^{24}$ TODOROV, T. Situações Extremas, p. 960. 
(...) Nós poderíamos reduzir essas virtudes elementares, praticadas cotidianamente nos campos pelos indivíduos comuns, e não por seres excepcionais, a três: a dignidade, ou a capacidade de agir de acordo com seus próprios princípios em vez de submeter-se às leis ou às ordens e, portanto, manter o respeito próprio; a preocupação pelo outro, que consiste em ocupar-se do bem-estar do próximo, sem esperar uma contrapartida exterior e sem buscar alguma justificação ideológica para seu ato (a pessoa humana é aqui o valor supremo); a espiritualidade ou a manutenção da vida do espírito, um esforço de elevação dirigido mais à humanidade do que aos indivíduos em particular. A conclusão que se impõe, a partir dessas observações, foi tirada por Des Pres: Acontece que o estado natural não é natural. 'A guerra de todos contra todos deve ser imposta pela força'.

(...) A experiência das situações extremas sugere antes que, se a preocupação pelo outro manifesta-se espontaneamente, sem nenhuma referência a um dever moral, as ações egoístas, ou as que usufruem de seu poder sobre outrem, não são, ainda assim, menos naturais. Poderíamos, portanto, afirmar que a moral opera uma escolha artificial no âmago de comportamentos naturais ${ }^{25}$.

Submergido pela inumanidade proveniente da situação extrema, causadora do estado de exceção, como definir a vida do homo sacer? Por que a existência ou inexistência deste sobrevivente mitológico localiza-se na encruzilhada, na indeterminação do espaço e tempo entre um ente suscetível a ser morto por qualquer um e portador de uma impureza ontológica para ser sacrificado, ocasionando-lhe a indiferença do direito humano e divino?

Tudo faz pensar que se encontra um conceito-limite do ordenamento social romano que, como tal, pode dificilmente ser explicado de modo satisfatório enquanto se permanece no interior do ius divinum e do ius humanum, mas que pode, talvez, permitir lançar uma luz sobre seus limites recíprocos. Mais do que resolver a especificidade do homo sacer, como se tem feito muito frequentemente, em uma pretensa ambiguidade originária do sagrado, calcada sobre a noção etnológica de tabu, é importante interpretar a sacratio como uma figura autônoma, perguntando se ela não permitiria por acaso lançar luz sobre uma estrutura política originária, que tem seu lugar em uma zona que precede a distinção entre sacro e profano, entre religioso e jurídico.

\section{CONSIDERAÇÕES FINAIS: UM “NOVO USO” É POSSÍVEL}

No livro que inaugurou o Programa Homo Sacer, Giorgio Agamben escreve:

O estado de exceção, no qual a vida nua era, ao mesmo tempo, excluída e capturada pelo ordenamento, constituía, na verdade, em seu apartamento, o fundamento oculto sobre o qual repousava o inteiro sistema político; quando as suas fronteiras se esfumam e se indeterminam, a vida nua que o habitava libera-se na cidade e torna-se simultaneamente o sujeito e o objeto do ordenamento político e de seus conflitos, o ponto comum tanto da organização do poder estatal quanto da emancipação dele. Tudo ocorre como se, no mesmo passo do processo disciplinar através do qual o poder estatal faz do homem enquanto vivente o próprio objeto específico, entrasse em movimento um outro processo, que coincide grosso modo com o nascimento da democracia moderna, no qual o homem como vivente se apresenta não mais como objeto, mas como

${ }^{25}$ TODOROV, T. Situações Extremas, p. 960-961. 
sujeito do poder político. Esses processos, sob muitos aspectos opostos e (ao menos em aparência) em conflito acerbo entre eles, convergem, porém, no fato de que em ambos o que está em questão é a vida nua do cidadão, o novo corpo biopolítico da humanidade ${ }^{26}$.

Em vista do estado de exceção que permanece nas democracias, o cidadão pode ser, de uma hora para outra, lançado pelo poder soberano para fora dos limites do estado de direito tornando-se, assim, num só golpe, objeto e não mais sujeito de tais direitos. Sua objetificação não pode vencer, todavia, uma certa força que nele permanece, um poder, se não mais de resistência, de persistência. No homo sacer contemporâneo a resiliência chega ao seu limite máximo, até esvair-se e, com isso, ceder espaço à mais absoluta resignação, à total entrega ao destino, transcendental ou mundano. Nesse ponto de inflexão, a vida nua se revela como pura potência: a carne que um dia apodrecerá é a mesma que denuncia, na elevada esfera da justiça, a violência do poder que a criou o poder soberano e o direito que o sustenta. No sarx, a que corresponde o homo sacer contemporâneo, encontra-se a chave para um novo uso das coisas, para a possibilidade de verdadeiramente viver-se "como não", abandonando-se as formas do poder, a saber, a perspectiva do poder sacralizado - um poder louvado por todos e usufruído por muito poucos - de modo a permitir-se o desmonte dos dispositivos que sustentam tal poder, sejam eles de caráter político, sejam de caráter jurídico ou mesmo religioso. Aqui, o homo sacer passa de mero objeto do poder soberano a sujeito da história. Elemento da mais profunda tensão entre as forças artificiais e as forças da natureza, o lugar destituído e destituinte que habita vê nascer, por sua própria vida, ou sobrevida, vida nua, o poder da espécie humana, a potência criativa, potência de deposição - do poder soberano.

No mundo secularizado, o hōs me torna-se, pois, urgente. Não para reestabelecer a religião, especialmente porque ela nunca deixou de estar, de fato, no poder soberano, mas para que se possa restituir aos seres humanos a possibilidade de usar, livremente, "as coisas" produzidas pela natureza e pelo homem. Conforme interpreta Agamben, Paulo Apóstolo não defendia o caráter impositivo das regras, não afirmava as regras enquanto comando, mas anunciava a lei como abertura para a libertação, na medida da fé dos homens. Tal fé pode ter, em Paulo, caráter tão concreto quanto a que o agnóstico contemporâneo demonstra assumir: a possibilidade da inteireza da vida humana.

\section{REFERÊNCIAS}

AGAMBEN, Giorgio. O uso dos corpos: Homo sacer, IV, 2. São Paulo: Boitempo, 2017. . O que resta de Auschwitz: o arquivo e a testemunha. São Paulo: Boitempo, 2008. . Homo Sacer: o poder soberano e a vida nua. Belo Horizonte: Editora UFMG, 2002.

BARBAGLiO, Giuseppe. As cartas de Paulo I. Tradução e Comentário. São Paulo: Loyola, 1989. BÍBLIA. A Bíblia de Jerusalém. 3. ed. São Paulo: Paulus, 2004.

CANTO SPERBER, Monique (Org.). Dicionário de ética e filosofia moral. São Leopoldo: Unisinos, 2013.

DETTWILER, Andreas; KAESTLI, Jean-Daniel; MARGUERAT, Daniel. Paulo, uma Teologia em Construção. São Paulo: Loyola, 2011.

${ }^{26}$ AGAMBEN, G. Homo Sacer: o poder soberano e a vida nua I, p. 16-17. 
DUNN, James D. G. A teologia do apóstolo Paulo. São Paulo: Paulus, 2003.

MOULIN, Anne Marie. O corpo diante da medicina. In: CORBIN, Alain; COURTINE, Jean-Jacques; VIGARELLO, Georges. História do corpo: As mutações do olhar: O século XX. 4. ed. Petrópolis: Vozes, 2011.

TODOROV, Tzvetan. Situações Extremas. In: CANTO-SPERBER, Monique.

ZUMSTEIN, Jean. A cruz como princípio de constituição da teologia paulina. In: DETTWILER, Andreas; KAESTLI, Jean-Daniel; MARGUERAT, Daniel. Paulo, uma Teologia em Construção. São Paulo: Loyola, 2011.

Recebido em: 15/02/2018

Aprovado em: 15/06/2018

\section{Correspondência para:}

Ricardo Geraldo de Carvalho

Rua Ernesto Alves Filho, 164 - Jardim Campos Elíseos

13060-057 Campinas, SP, Brasil 